\title{
The Saudi Experience of Health-Related Social Media Use: A Scoping Review
}

\author{
Dalia Yahia M. El Kheira Dhuha Nahar Boumarah ${ }^{b}$ \\ Fatimah Mousa Bukhamseen $^{b}$ Jumana Husain Masoudi ${ }^{b}$ Leila A. Boubshait ${ }^{a}$ \\ aDepartment of Family and Community Medicine, College of Medicine, Imam Abdulrahman Bin Faisal University, \\ Dammam, Saudi Arabia; ${ }^{b}$ College of Medicine, Imam Abdulrahman Bin Faisal University, Dammam, Saudi Arabia
}

\section{Keywords}

Health care · Social media · Saudi Arabia - Telemedicine ·

Social networks

\begin{abstract}
Objectives: Social media (SM) are evolving and dynamic applications which can be used in health-care settings to enhance professional networking and education; patient communication, care, and education; public health programs; organizational promotion; and research. This review aims to analyze, summarize, and describe the current Saudi experience of SM use for health. Methods: A MEDLINE/PubMed electronic database search was performed in July 2020 utilizing the Preferred Reporting Items for Systematic Reviews and Meta-Analyses (PRISMA) recommendations. The initial search has yielded a total of 263 articles, of which 25 met our inclusion criteria. Results: In Saudi Arabia, the literature reports a high interest in using SM for health-related purposes among the public, with a prevalence of $>51 \%$. The Saudi population has been found to highly favor the use of WhatsApp and Twitter for gaining and exchanging knowledge. Multiple facilitators and barriers have been identified and further categorized based on the users' population, such as general public, health-care practitioners, and patients with specific conditions. Overall, the common facilitator and
\end{abstract}

barrier between all users' population categories were found to be younger age and lack of time, respectively. Conclusion: SM use for health-care activities is increasing in Saudi Arabia. Thus, it is important for SM-based health education programs to target specific population and patients' demographics with programs tailored to their particular interests and needs. This is particularly evident in the current achievements and future plans of the Saudi Ministry of Health.

(c) 2021 The Author(s)

Published by S. Karger AG, Basel

\section{Introduction}

Social media (SM) are evolving and dynamic applications with hundreds of platforms and millions of users. They have been defined as "a group of Internet-based applications that build on Web 2.0 technology and allow users to create and exchange their contents" [1]. Web 2.0 technology is based on enabling individuals to actively discuss, modify, and distribute the published information, in comparison with Web 1.0 technology, where individuals passively obtain information from the Internet $[2,3]$. The term "Internet-based SM applications" refer to a multi-suite set of Web technologies such as blogs, discussion communities, social networks, collaborative

karger@karger.com www.karger.com/sjh

Karger $\stackrel{\text { ' }}{5}$

GOPEN ACCESS
C 2021 The Author(s).

Published by S. Karger AG, Basel

This is an Open Access article licensed under the Creative Commons Attribution-NonCommercial-4.0 International License (CC BY-NC) (http://www.karger.com/Services/OpenAccessLicense), applicable to the online version of the article only. Usage and distribution for commercial purposes requires written permission.
Correspondence to:

Dalia Yahia M. El Kheir, dyme@ rocketmail.com 
projects, virtual game worlds, and virtual social worlds. People access these SM platforms for health-related purposes in addition to other subjects [4]. Moreover, SM can be utilized to improve health-care professional networking, education, patient communication, patient care, public health program awareness, organizational promotion, and research.

Worldwide, the use of SM continues to progress tremendously, with the number of active users reaching up to 4.1 billion [5]. In 2020, Facebook had 2.6 billion users and was ranked as the most popular SM platform [6]. Interestingly, the use of SM for health-related purposes is increasingly expanding, with almost $80 \%$ of Internet users utilizing it to look for online health information. Among the Saudi population, in particular, an estimated 18.3 million people were SM users in 2020 [7]. According to a recent Saudi study, approximately two-thirds of the population relied on official government SM accounts to acquire knowledge regarding the pandemic of coronavirus disease 2019 (COVID-19) [8].

With regard to addressing key health behaviors, such as physical inactivity, smoking, obesity, poor diets, and alcohol misuse, online social networks appear to be a cost-effective tool for public health campaigns. It reaches a wider audience by allowing them to participate through sharing their knowledge and experiences [9]. An example of SM use in health promotion is the following experience of the Centers for Disease Control and Prevention (CDC). In 2009, the CDC used Twitter to raise the awareness about the pandemic of $\mathrm{H} 1 \mathrm{~N} 1$, which reached more than 1.2 million followers $[10,11]$. This incident showed the strength of SM as a health promotion tool [12].

Nevertheless, despite the fact that SM use has enormous benefits, its implementation within the health-care society could be a challenge. As the public can participate in creating content in SM, it might pose a risk of spreading incorrect health-related information. Thus, it is essential to have reliable communication channels, where information disseminated is continuously monitored and verified [4]. This issue could be aggravated by some patient attitudes such as described by Sadah et al. [13] who mentioned that about $40 \%$ of Americans consider information on SM to be more reliable than a health-care professional's advice when conflict is present.

In Saudi Arabia, the use of SM networks in health care is developing and increasing rapidly. In this scoping review, we analyze, summarize, and describe the current literature exploring the Saudi experience with the aim to answer the question of how the Saudi population is using SM for health-related purposes. We examined health-re- lated SM use in terms of Saudi population interest in using SM for health-related purposes, users' characteristics, types of SM platforms used, and facilitators and barriers to use SM in health-care purposes. Such information is necessary to advance the successful future adoption and optimal utilization of various SM networks and technology in the health-care service provision in Saudi Arabia.

\section{Materials and Methods}

\section{Search Strategy}

We followed the Preferred Reporting Items for Systematic Reviews and Meta-Analyses (PRISMA) recommendations when performing this scoping review. A PubMed electronic database search was performed between 1 and 31 July 2020. To avoid bias, the research question was formulated in advance, based primarily on clinical relevance, before exploring the available evidence. SM and Saudi were the principal search terms used in combination with one of the following: chronic diseases, health, and health education. The published studies' references were also searched manually for relevant studies.

\section{Study Selection}

Three of us (D.B., F.B., and J.M.) were responsible for data collection individually, with any disagreement resolved through discussion between all reviewers, including D.A. and L.B. The initial search yielded a total of 263 articles, of which 116 studies were found potentially relevant from their titles and had their abstracts reviewed. Twenty-nine articles met all following criteria [1]: studies conducted in Saudi Arabia [2], articles discussing SM use in health care [3], and articles discussing at least one of the following: the rate of interest of health-related SM use, commonly used platforms and the type of use for each platform, characteristics of users, and facilitators and barriers to SM use in health-care-related purposes. After reviewing the full text of these 29 articles, 4 articles were excluded using our exclusion criteria [1]: review articles that did not include Saudi studies [2] and articles discussing SM use that is unrelated to health care. Thus, a total of 25 articles were available for our final data extraction and analyses. The selection process of the studies is presented in a PRISMA flow diagram (Fig. 1).

\section{Data Extraction}

Data extraction was performed via a data extraction tool developed, a priori, from previously published extraction tools used by national and international studies evaluating SM use in health care. The extraction tool was used to extract information from the eligible studies, 25 articles in total. The following information is included in the extraction table: the authors, year of publication, study design, sample size, characteristics of the population, aim of the study, and study results, including healthrelated interest of use, types of health-related SM use, most common platforms used, and perceived facilitators and barriers of SM use in health care.
El Kheir/Boumarah/Bukhamseen/ Masoudi/Boubshait 


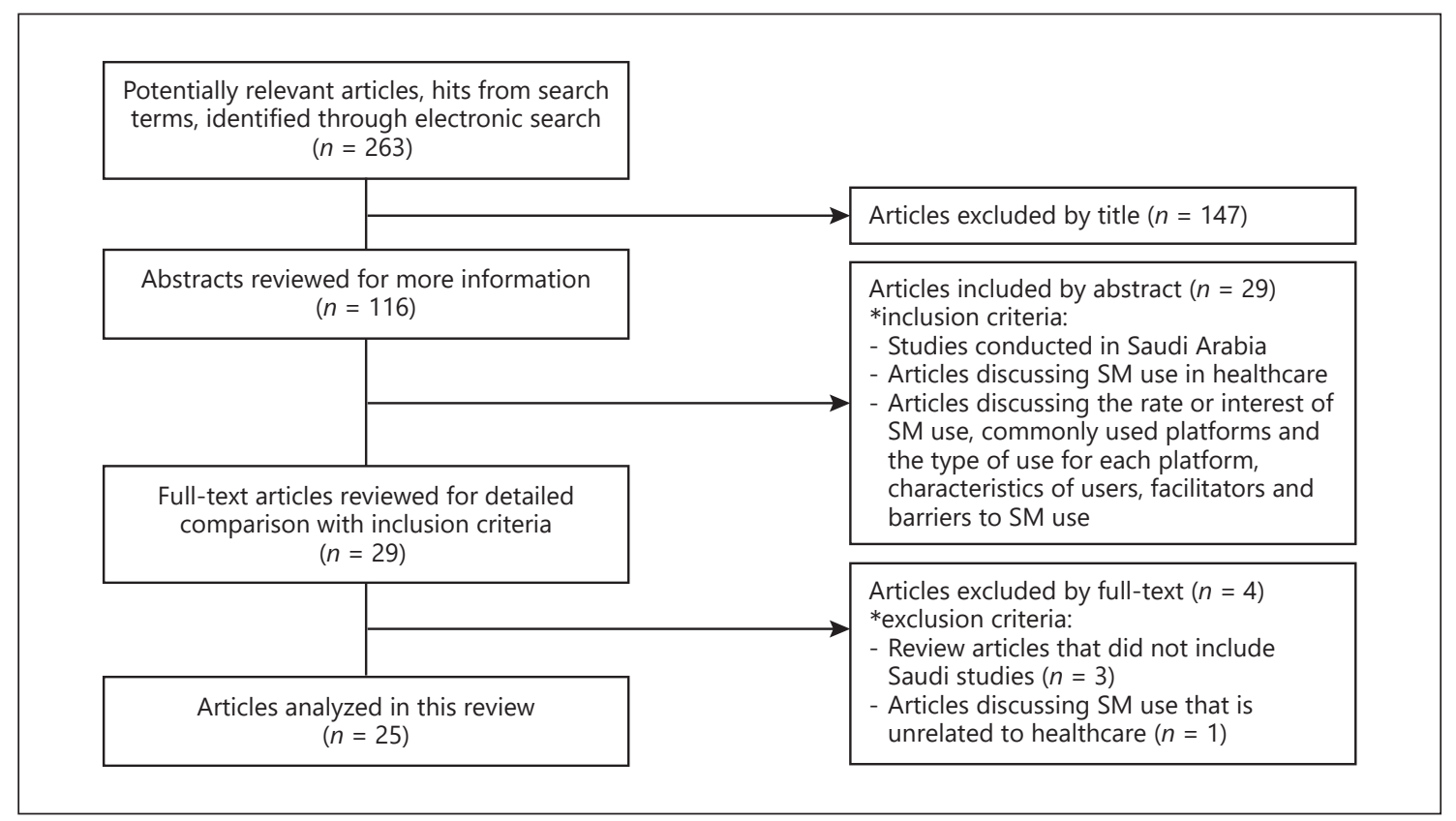

Fig. 1. PRISMA flow diagram for the Saudi studies. PRISMA, Preferred Reporting Items for Systematic Reviews and Meta-Analyses.

\section{Results}

The population studied in the 25 articles reviewed included the general public (10 articles), patients with specific disease conditions (5 articles), and health-care practitioners ( 10 articles). The summary of the 25 analyzed articles is shown in Table 1.

\section{Interest in Using SM for Health-Care Purposes}

In Saudi Arabia, on average, articles reported a high interest of the public to use SM for health-care-related purposes, with a minimum reported rate of interest of $51 \%$ [14]. When examining the frequency of SM use, the general public tend to spend $>3$ hours daily [12]. However, this rate decreases to once per week when it comes to searching health-related information on SM [15] or other Internet search engines [16].

Similarly, patients with specific disease conditions showed a high interest in using SM to learn about their disease and its management. Diabetic patients were reported to use SM for a minimum of 1 hour per day [17]. Celiac patients reported a similar pattern of daily usage [18]. Nonetheless, in a similar pattern to the general public, the majority of diabetic patients are using SM every few months to search for health-related information on Internet search engines [19]. Likewise, the majority of health-care practitioners were using SM on a daily basis with a minimum of 1 hour per day [20-24]. While most of them have used SM for professional purposes $[25,26]$, none of the articles discussed how much of their time was devoted to using SM specifically for this purpose.

\section{Types of Health-Related SM Use}

There are different types of SM use for health-related activities reported in the Saudi literature. The most common was gaining and exchanging knowledge, either related to health in general [15] or to a specific health condition's diagnosis $[1,3,19,27]$, management $[12,18,28]$, and prevention $[14,17]$.

In most of the articles, participants showed a high interest in using SM to communicate and follow SM accounts of their physicians $[12,16]$, most prominently in studies discussing patients with specific disease conditions $[17,18]$. Communicating with other patients of similar conditions [17], sharing personal experiences [12, 16, $17,29]$, and providing or seeking support through online communities and resources [29] have been also reported in the Saudi literature.

Although health-care practitioners use SM mainly for personal purposes, a majority show a high interest in using it for professional purposes [21, 22, 30]. Health-care practitioners reported improving their professional 


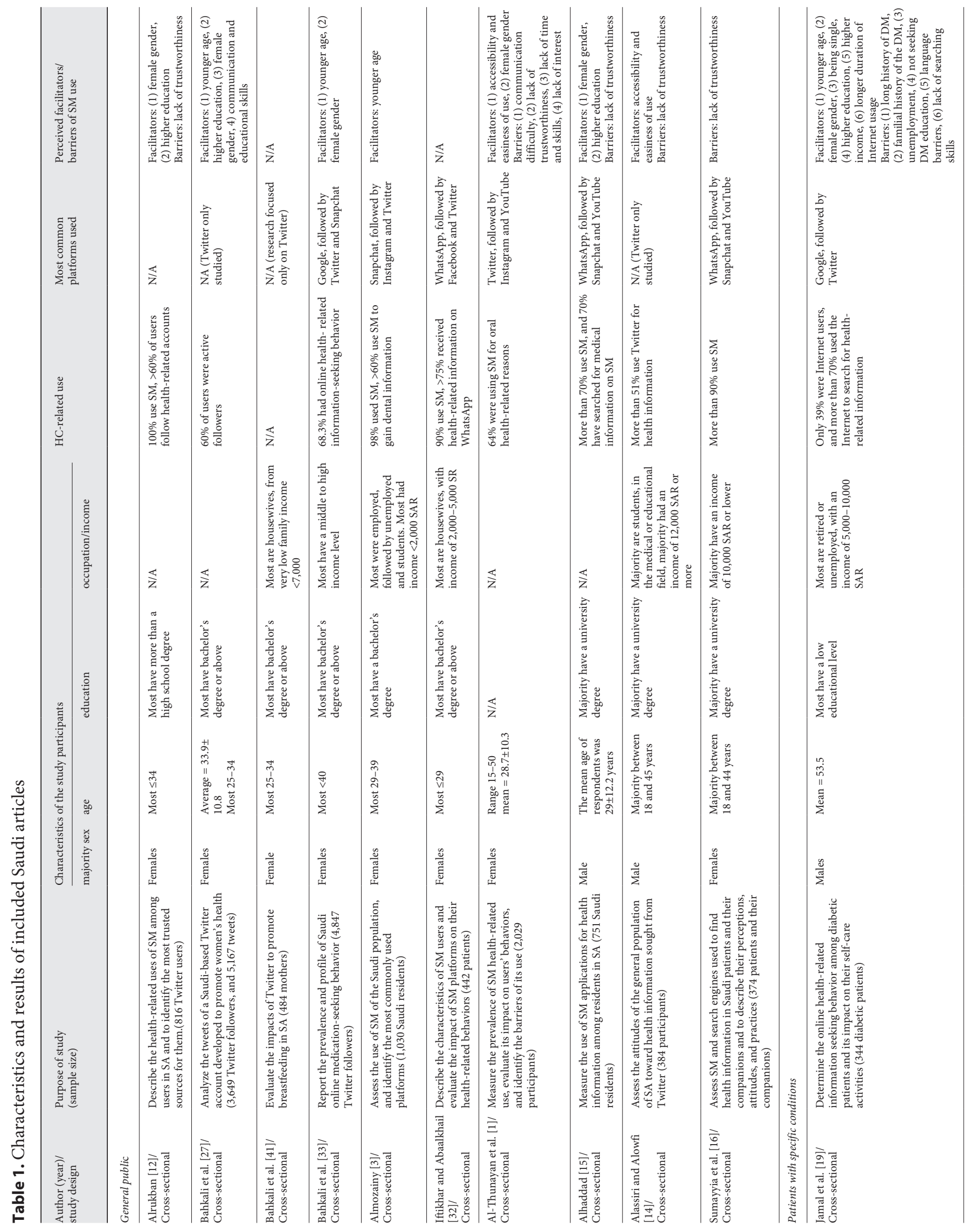




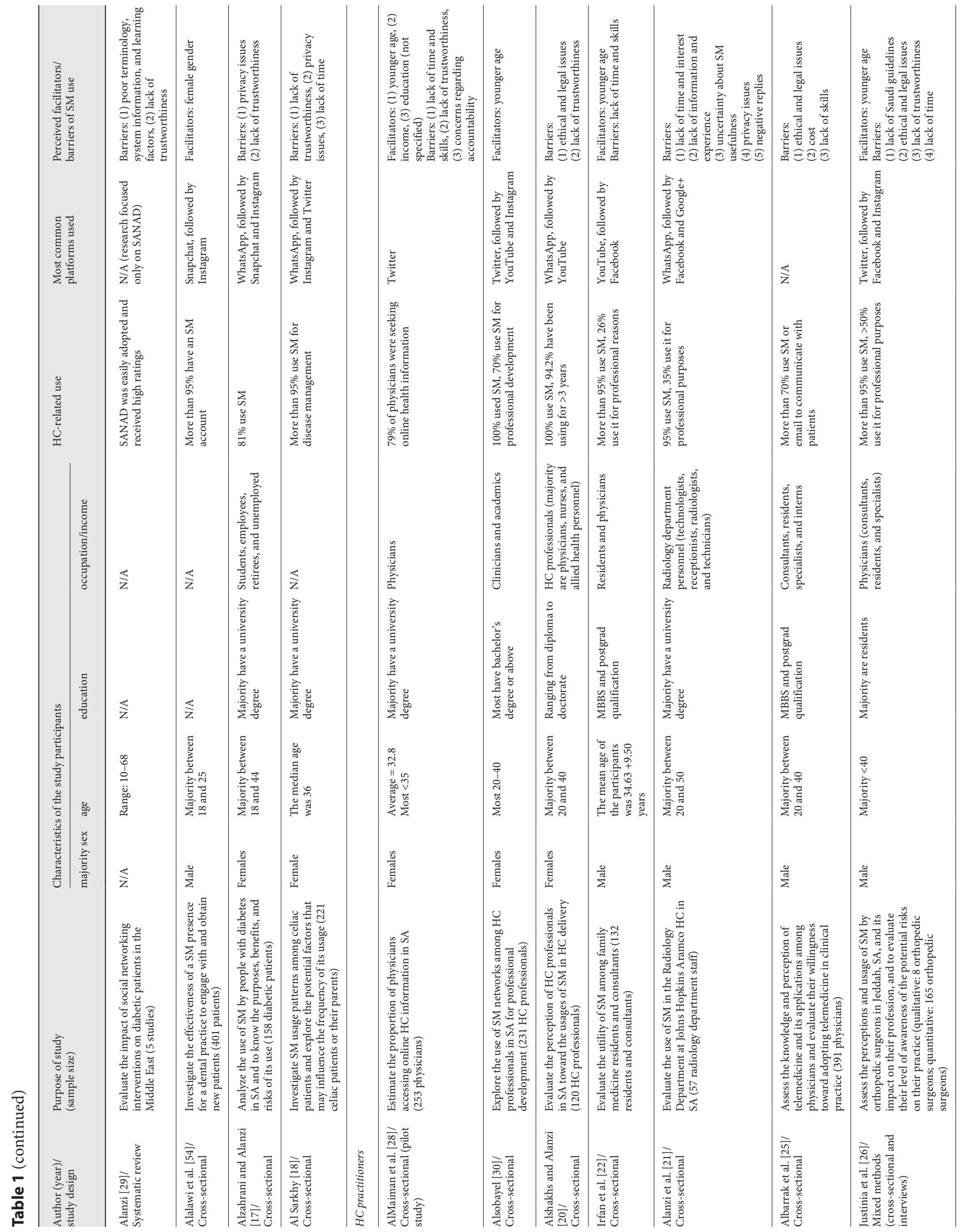




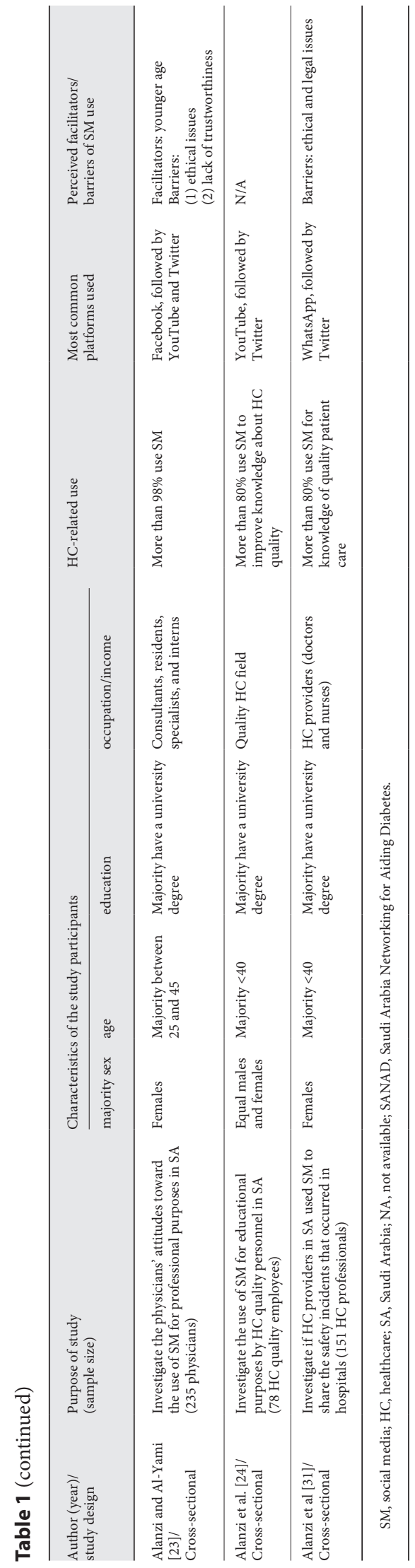

knowledge and skills $[23,24,31]$ by sharing the literature [29], work experiences, and medical knowledge [20, 22, $25,26]$. In addition, many articles reported health-care practitioners participating in health promotion $[12,24$, 29,31 ] by raising awareness and disseminating general advice through SM platforms [26]. In regard to healthcare delivery by online consultations $[14,23,25,26]$, health-care practitioners showed a lower tendency of using SM for this purpose in most articles. Other reported types of use by health-care practitioners include networking, self-promotion, employment and research opportunities, and sharing incidents that affect patient safety [24, $30,31]$.

\section{Common SM Platforms}

It has been found that different populations favor different SM platforms for both general use and health-related activities, and that people may use $2-4$ different SM platforms. WhatsApp was reported as the most popular platform among the Saudi population, with a usage rate of $89.8 \%$, followed by Twitter [15, 20, 21,32]. Details regarding the most commonly used SM platforms reported in each article can be reviewed in Table 1 .

\section{Characteristics of SM Users}

We reviewed the SM users' characteristics in the Saudi articles we analyzed. We observed that based on studies that examined it, most of the participants were married $[19,22,26,32,33]$. In addition, since all the studies included in this section took place in Saudi Arabia, almost all participants were Saudi residents and, for the majority, the country of origin was Saudi Arabia [3, 30, 32, 33]. Details of other participants' characteristics (age, education, occupation, and income) are presented in Table 1.

\section{Facilitators of SM Use in Health Care}

Many Saudi articles have discussed different participants' characteristics and SM platforms' features that increased SM use for health-care-related activities. Younger age and female gender were reported as the main users' characteristics facilitating the use of SM for health-related purposes [12, 19, 28, 30]. Specific SM platforms' features such as easy accessibility and cost-effectiveness were also associated with higher rates of use [1,27]. Other facilitators are presented in Table 1 and further categorized in Table 2.

\section{Barriers against SM Use in Health Care}

Barriers to using SM to seek health-related information were discussed by several Saudi articles. Lack of 
trustworthiness and disease-specific information was identified as important barriers to the use of SM for health care among the general population $[1,18]$. Additionally, health-care practitioners reported the risk of breaching patients' privacy as one of the factors preventing the adoption of SM in health care [21]. Different barriers reported by the general public and health-care practitioners are presented in Table 1 and further categorized in Table 2 .

\section{Discussion}

To our knowledge, this is the first scoping review article analyzing and quantifying the information available on the use of SM for health-care-related activities in Saudi Arabia. In this review, we describe SM users' characteristics, their reasons and types of use, in addition to SM utilization opportunities, and utilization facilitators and barriers in Saudi Arabia.

\section{Interest in Using SM for Health-Care Purposes}

In Saudi Arabia, the literature reports a high interest in using SM for health-related purposes among the public, with a minimum reported rate of interest of $51 \%$ [ 1 , $12,14]$. In general, the daily usage of SM was relatively high when compared to the time spent on using SM for health-related activities [17, 19]. Similarly, a cross-sectional study among Vietnamese youths reported that $73 \%$ of participants are interested in health-related information shared on SM [34]. Another study conducted by Ghweeba et al. [35] showed that individuals spend $>30 \%$ of their time on SM engaging and reading health-related information. Regarding health-care practitioners, most residents, junior, and senior physicians were reported to be using SM daily, spending 3-6 hours on SM per week [36], and only a minority reported no use at all [37].

\section{Types of Health-Related SM Use}

The most common reason, as mentioned by several Saudi articles, for using health-related SM was for gaining and exchanging knowledge $[3,19,27,30]$. In addition, general pubic showed high interest in using SM for communicating with their physicians and other patients with similar conditions $[12,16,17]$. Other types of use include providing support to patients, raising awareness, promoting health, and sharing the latest news on health care $[12,19,27,29,30]$. Saudi health-care professionals utilized SM for self-promotion and to explore employment or research opportunities [30]. The international audi-

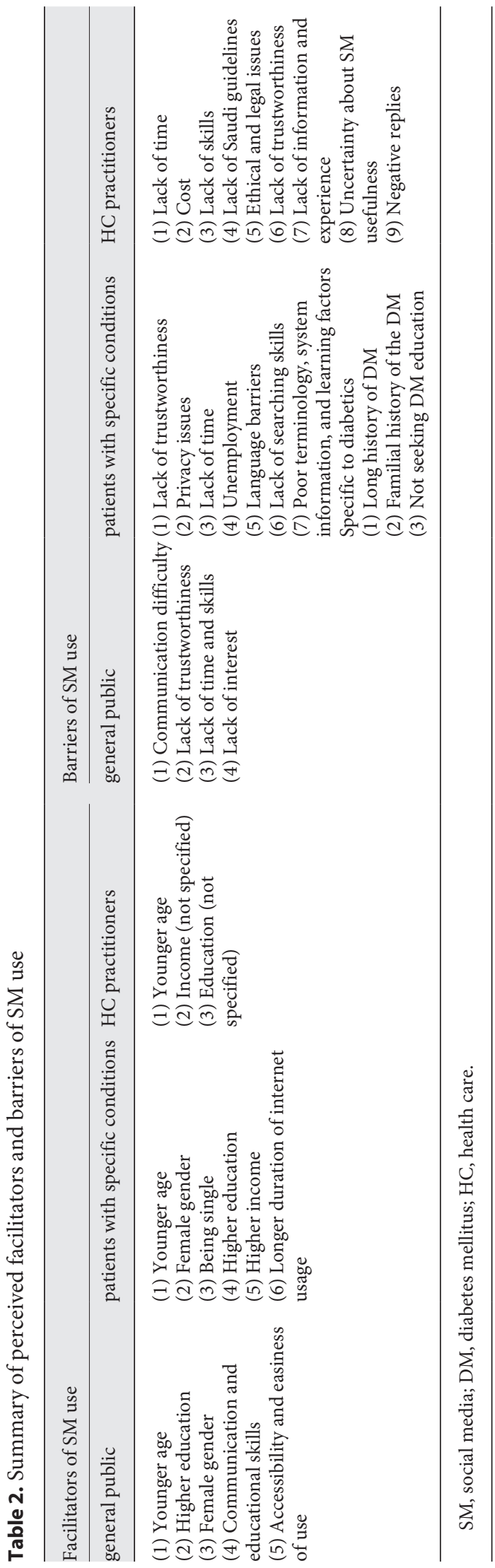


ence used SM for similar reasons, as reported by multiple articles, with goals such as connecting with other patients and finding social support described as two of the most common drivers of health-related SM use internationally $[4,38]$.

\section{Common SM Platforms}

It has been found that different populations favor different SM platforms for both general use and health-related activities, and that people may use 2-4 different SM platforms [38]. The Saudi population has been found to highly favor the use of WhatsApp as a SM platform, with usage rate as high as $89.8 \%$, going up to $96.7 \%$ among health-care practitioners $[15,20,21,32]$, while some of international studies have reported different SM platforms used for health-related activities, namely, social network sites, followed by discussion forums and blogs [39]. Facebook was rated as the highest used SM platform internationally, with adoption rates of hospitals as high as $99.4 \%$, followed by Twitter $[34,38,40]$.

\section{Characteristics of SM Users}

General Saudi public users of SM for health-care activities are predominantly married [19, 32, 33], female participants [3,12, 19, 30,32], below the age of 40 years $[3,12,32,33,41]$, bachelor degree holders $[3,30,32,33]$, with the majority having middle to high income, monthly salary ranging from over 2,000 to $10,000 \operatorname{SAR}[3,19,32$, 33 , with a combination of employed and unemployed SM users [3, 19, 30, 32]. The Saudi literature investigated mainly Saudi residents with the country of origin being also Saudi Arabia [3, 30, 32, 33]. Similar to findings in the Saudi public SM users, several international studies reported that the majority of SM users for health-care activities are also predominantly females $[13,34-39,42]$ and young adults (between 18 and 35 years of age) $[13,34$, $35,38,42]$, highly educated (possessing or obtaining a college degree) $[34,35,38,39,42]$, but with varying marital status [34, 35, 39].

\section{Facilitators of SM Use in Health Care}

Many Saudi articles have discussed different participants' characteristics that increased SM use such as being young, female, and having a higher level of education and income $[12,19,27,28,30,32]$. The same findings were also described by a number of international studies: being young, female, and having a higher income and higher education were associated with higher use of SM for health-related activities [2, 13, 35, 37-39, 43]. One international study also examined the elderly use of SM for health-related activities, where both the breadth and depth of their daily technology use, together with their attitude and feelings toward technology, had a positive association with higher SM use [2]. Furthermore, individuals with chronic health conditions and those who perceived the usefulness of the information on SM had an increased involvement in sharing and seeking health-related information via SM $[35,44]$.

Features of SM platforms that increased population use of SM for health-related activities were also reported in the Saudi literature. These features included facilitating the interaction between the general public and healthcare professionals, being easily accessible and cost-effective, available for all age-groups, and allowing easy extraction of health-related information $[1,27]$. In addition, the professional communication and educational skills of the health practitioners providing information on SM platforms, and their adherence to evidence-based information were also found to contribute to increased use of SM by the public for sharing health-related information. SM platform features facilitating the use among the international public were also described in a couple of articles, such as being easily accessible, and cost-effective, userfriendly, in addition to their portability, speed, simplicity, and ability to update and preserve the anonymity of the user $[35,45,46]$.

\section{Barriers against SM Use in Health Care}

Barriers to using SM to seek health-related information were discussed in several Saudi articles. SM platform features that lead to lower interest in using SM for healthrelated purposes among the general public include lack of trustworthiness [18], lack of disease-specific information, and the difficulty in communicating with health-care experts $[1,28]$. Health-care practitioners have reported in multiple articles that lack of time $[21,22,26]$ and lack of skills $[14,28]$ were the main reasons behind not using SM more frequently for professional purposes. These barriers were similarly reported by the general public $[1,18,28]$.

Other barriers that might avert health-care practitioners from using SM in health care are the risk of sharing patients' private information, thus breaching the patients' privacy [21]. In addition, health-care practitioners may avoid sharing health advice on SM due to confidentiality, liability, reputation, and misinformation issues $[20,26$, 31].

Our scoping review findings are corroborated by a recent Saudi study reporting on the major barriers against implementing SM in health-care management, as identified by leading health-care professionals and decision-
88

Saudi J Health Syst Res 2021;1:81-92 DOI: $10.1159 / 000516473$
El Kheir/Boumarah/Bukhamseen/ Masoudi/Boubshait 
makers in Saudi Arabia [29]. Identified barriers included shortage in mHealth expertise and human resources, need for targeted funding and infrastructure investments, and standardization of legal, privacy, and regulatory directives, in addition to general health-care organizational and bureaucratic impediments. The study also suggested several solutions for these barriers that revolved around the need to establish appropriate leadership and clinical environment to foster SM adoption in the current Saudi health-care system [29].

Internationally, some of the commonly identified barriers to SM use were lack of time, lack of computer or Internet access, lack of skills and experience using the computer, and the possibility of acquiring misleading information via SM [10, 13, 36, 39, 47]. In addition, males, elderly, those with poor education, non-English speakers, and those from a black ethnicity were associated with less SM-related health-seeking behavior $[10,34,36,46]$. Furthermore, privacy and confidentiality issues were also reported as important barriers to SM use in health-related communication [38, 45, 47]. Moreover, physicians reported that their work requirements, their fear of saying the wrong thing online, and the lack of guidelines and institutional support were all factors that deterred them from using SM for health-related communication [36].

\section{Saudi Arabia Ministry of Health e-Health Project: \\ Current Achievements and Future Plans}

The Ministry of Health (MOH) has recognized the trend of increased SM use in Saudi Arabia and has embraced the change by creating $\mathrm{MOH}$ accounts on various $\mathrm{SM}$ platforms to engage with the Saudi public. The $\mathrm{MOH}$ was keen to join those SM networks known to be popular among Saudi citizens. The MOH's first accounts on SM were on Twitter and YouTube, both of which were found by several Saudi articles to be popular SM platforms among Saudis. In 2019, the MOH Twitter account, established in April 2011, had 2.04 million followers and 52.7 thousand tweets. The $\mathrm{MOH}$ Facebook page, created in April 2011, had almost 600 thousand follows and likes, and the page was rated 4.0 out of 5 . During the COVID-19 pandemic, Twitter and Facebook accounts gained a huge amount of attention with a dramatic increase in the number of followers as updates regarding new cases are posted on them daily. Currently, August 2020, the Twitter account has 4.2 million followers and 55.7 thousand tweets and the Facebook page, which is now rated 4.8 out of 5, has 2.3 million followers. The YouTube account was also created in April 2011, and they currently, August 2020, have 534 videos with an overall view count of 48.9 mil- lion. The first Instagram post was uploaded in June 2017, and the MOH team has since then uploaded 946 posts with a total of 576 thousand followers.

In 2016, in its annual report, the $\mathrm{MOH}$ reported that by creating several infographics and videos covering important health-related topics, as well as $\mathrm{MOH}$ project achievements, it was able to increase awareness of the followers (individuals and communities) about these healthrelated issues by delivering reliable, timely, and easily digestible information. With those findings in mind, the $\mathrm{MOH}$ was able to raise awareness of the COVID-19 pandemic through similar means of videos and infographics shared on their SM platforms.

It is worthy of mentioning that the $\mathrm{MOH}$ has launched several e-services through their portal and different apps that would benefit the citizens. One of the apps is "Seha" that provides medical consultations from accredited doctors allowing patients to connect with the doctors by chat, voice, or video calls. They are also able to evaluate their experience after the consultation through the app [48]. The other app is "Mawid" that allows the patients to book, cancel, or reschedule appointments at primary healthcare centers, in addition to managing their referral appointments [49]. Another service offered through this app is the e-prescription service where the patient can obtain a prescribed medication from any pharmacy by a consultation through the app without the need to see a doctor [50]. In addition, the $\mathrm{MOH}$ has a call center (937) that provides a wide range of services such as medical consultations, appointment reservations at PHCs, and technical support for the $\mathrm{MOH}$ apps through telephone calls, SM, or email. The use of such services has become vital during the COVID-19 pandemic. In the month of July 2020 alone, the call center received over 2.9 million calls [51]. In the wake of the pandemic, the $\mathrm{MOH}$ services expanded to include interactive services through a designated WhatsApp number, as well as a new app "Tetamman" [52]. The app "Tetamman" is aimed to provide care and protection for those isolated or quarantined due to COVID-19 by including educational information, health status follow-ups, a countdown indicator for isolation, and other services that will ensure their safety and full recovery [53].

The strength of our study lies in our comprehensive and systematic approach to analyze and quantify the amount of information available on the use of SM for health-care-related activities in Saudi Arabia. Nevertheless, our study has some limitations mainly that we have reviewed studies published in the English language only, and we have adopted the original researchers' 
interpretation(s), as published in the individually reviewed articles. Due to the limited number of Saudi studies, an effort was made to comprehensively retrieve all published articles fulfilling the inclusion criteria, regardless of their methodological quality. Future reviews addressing the use of SM in Saudi Arabia should focus on assessing methodological quality to enhance the reliability of reported data.

\section{Conclusion}

In conclusion, SM use for health-care activities is increasing in Saudi Arabia [1], mostly among female individuals and younger adults $[3,12,19,30,32,33,41]$. Studies revealed variability in the topics searched among different population demographics $[29,43]$. Thus, it is important for SM-based health education programs to target specific population and patients' demographics with programs tailored to their particular interests and needs.

\section{Recommendations}

There are only a limited number of published Saudi studies, to date, investigating the use of SM for healthcare-related activities by the Saudi population and healthcare practitioners. Majority of the available Saudi literature focused on describing the characteristics of SM users in health care and their preferred SM networks. However, little information is available concerning the impact of SM on health behaviors and status of the users. In addition, little is known about the implementation of SM in health care, especially with regard to communicating with patients and overall management and follow-up of patients' health conditions. Thus, further research is recommended in these areas to assess the current and future utilization and impact of SM platforms on health care in Saudi Arabia.

\section{Statement of Ethics}

Our current submission is a scoping review of publicly available published literature. As such, it did not require a formal Ethical Approval, as per the requirements of the Institutional Review Board of Imam Abdulrahman Bin Faisal University.

\section{Conflict of Interest Statement}

The authors have no conflicts of interest to declare.

\section{Funding Sources}

The authors did not receive any funding.

\section{Author Contributions}

D.Y.E. conceived the concept and design choice for the study and has a role in implementing the study and data collection, analysis, and interpretation of data, and she contributed substantially to the writing of this article and read, edited, and approved its final version. L.A.B. has a role in implementing the study and data collection, and she read, edited, and approved its final version. D.N.B. has a role in conducting the study and data collection, analysis, and interpretation of data, and she contributed substantially to the writing of this article, read, edited, and approved its final version. F.M.B. has a role in conducting the study and data collection, analysis, and interpretation of data, and she contributed substantially to the writing of this article, read, edited, and approved its final version. J.H.M. has a role in conducting the study and data collection, analysis, and interpretation of data, and she contributed substantially to the writing of this article, read, edited, and approved its final version. All authors have critically reviewed and approved the final draft and are responsible for the content and similarity index of the manuscript.

\section{References}

1 Al-Thunayan AM, Alsalhi R, Elmoazen R. Role of social media in dental health promotion and behavior change in Qassim province, Saudi Arabia. Int J Med. 2018;4(2):98-103.

2 Parida V, Mostaghel R, Oghazi P. Factors for elderly use of social media for health-related activities. Psychol Mark. 2016;33(12):1134-41.

3 Almozainy M. Assessing the use of social media as a source of information related to dentistry in Saudi Arabia. J Dent Health Oral Disord Ther. 2017;8(7).
4 Smailhodzic E, Hooijsma W, Boonstra A, Langley DJ. Social media use in healthcare: a systematic review of effects on patients and on their relationship with healthcare professionals. BMC Health Serv Res. 2016;16:442. Epub 2016 Aug 27. PubMed PMID: 27562728; PubMed Central PMCID: PMCPMC5000484.

5 Johnson J. Worldwide digital population as of October 2020. 2021. Available from: https:// www.statista.com/statistics/617136/digitalpopulation-worldwide/.
6 Tankovska H. Global social networks ranked by number of users 2020. 2021. Available from: https: //www.statista.com/statistics/272014/global-social-networks-rankedby-number-of-users/.

7 Technology MoCaI. Over 18 million users of social media programs and applications in Saudi Arabia 2016. [cited 2021 Feb 7]. Available from: https://www.mcit.gov.sa/en/media-center/news/89698. 
8 Alnasser AHA, Al-Tawfiq JA, Al Kalif MSH, Alobaysi AMA, Al Mubarak MHM, Alturki $\mathrm{HNH}$, et al. The positive impact of social media on the level of COVID-19 awareness in Saudi Arabia: a web-based cross-sectional survey. Infez Med. 2020;28(4):545-50. Epub 2020 Dec 2. PubMed PMID: 33257629.

9 Plackett R, Kaushal A, Kassianos AP, Cross A, Lewins D, Sheringham J, et al. Use of social media to promote cancer screening and early diagnosis: scoping review. J Med Internet Res. 2020;22(11):e21582. Epub 2020 Nov 10. PubMed PMID: 33164907; PubMed Central PMCID: PMCPMC7683249.

10 Han CJ, Lee YJ, Demiris G. Interventions using social media for cancer prevention and management: a systematic review. Cancer Nurs. 2018;41(6):E19-31. Epub 2017 Jul 29. PubMed PMID: 28753192; PubMed Central PMCID: PMCPMC5787052.

11 Padrez KA, Ungar L, Schwartz HA, Smith RJ, Hill S, Antanavicius T, et al. Linking social media and medical record data: a study of adults presenting to an academic, urban emergency department. BMJ Qual Saf. 2016; 25(6):414-23. Epub 2015 Oct 16. PubMed PMID: 26464519

12 ALrukban A. The health related uses of social media among users in Saudi Arabia. Int J Med Sci Public Health. 2014;3(12):1492-7.

13 Sadah SA, Shahbazi M, Wiley MT, Hristidis V. A study of the demographics of web-based health-related social media users. J Med Internet Res. 2015;17(8):e194. Epub 2015 Aug 8. PubMed PMID: 26250986; PubMed Central PMCID: PMCPMC4705027.

14 Alassiri SA, Alowfi AS. Public's attitudes toward health information on Twitter: a crosssectional survey based on the Saudi Population. Cureus. 2019;11(10):e5863. Epub 2019 Nov 26. PubMed PMID: 31763086; PubMed Central PMCID: PMCPMC6834101.

15 Alhaddad MS. The use of social media among Saudi residents for medicines related information. Saudi Pharm J. 2018;26(8):1106-11. Epub 2018 Dec 5. PubMed PMID: 30510470; PubMed Central PMCID: PMCPMC6257910.

16 Sumayyia MD, Al-Madaney MM, Almousawi FH. Health information on social media. Perceptions, attitudes, and practices of patients and their companions. Saudi Med J. 2019; 40(12):1294-8. Epub 2019 Dec 13. PubMed PMID: 31828284

17 Alzahrani A, Alanzi T. Social media use by people with diabetes in Saudi Arabia: a survey about purposes, benefits and risks. Diabetes Metab Syndr Obes. 2019;12:2363-72. Epub 2020 Feb 6. PubMed PMID: 32009810; PubMed Central PMCID: PMCPMC6859467.

18 Al Sarkhy A. Social media usage pattern and its influencing factors among celiac patients and their families. Saudi J Gastroenterol. 2020;26(2):99-104. Epub 2020 Feb 8. PubMed PMID: 32031161; PubMed Central PMCID: PMCPMC7279077.
19 Jamal A, Khan SA, AlHumud A, Al-Duhyyim A, Alrashed M, Bin Shabr F, et al. Association of online health information-seeking behavior and self-care activities among type 2 diabetic patients in Saudi Arabia. J Med Internet Res. 2015;17(8):e196. Epub 2015 Aug 14. PubMed PMID: 26268425; PubMed Central PMCID: PMCPMC4642387.

20 Alshakhs F, Alanzi T. The evolving role of social media in health-care delivery: measuring the perception of health-care professionals in Eastern Saudi Arabia. J Multidiscip Healthc. 2018;11:473-9. Epub 2018 Oct 3. PubMed PMID: 30275699; PubMed Central PMCID: PMCPMC6157575.

21 Alanzi TM, Alshahrani B. Use of social media in the Department of Radiology at Johns Hopkins Aramco Healthcare in Saudi Arabia. J Multidiscip Healthc. 2018;11:583-9. Epub 2018 Nov 10. PubMed PMID: 30410345; PubMed Central PMCID: PMCPMC6200085.

22 Irfan KS, Farhana I, Eiad AF, Nassr AM, Al Mohammed AQ, Maya N, et al. Family physicians' utility of social media: a survey comparison among family medicine residents and physicians. Afr Health Sci. 2018;18(3):81727. Epub 2019 Jan 4. PubMed PMID: 30603016; PubMed Central PMCID: PMCPMC6307000.

23 Alanzi T, Al-Yami S. Physicians' attitude towards the use of social media for professional purposes in Saudi Arabia. Int J Telemed Appl. 2019;2019:6323962.

24 Alanzi T, Al-Habib DK. The use of social media by healthcare quality personnel in Saudi Arabia. J Environ Public Health. 2020;2020: 1417478.

25 Albarrak AI, Mohammed R, Almarshoud N, Almujalli L, Aljaeed R, Altuwaijiri S, et al. Assessment of physician's knowledge, perception and willingness of telemedicine in Riyadh region, Saudi Arabia. J Infect Public Health. 2021 Jan; 14(1):97-102.

26 Justinia T, Alyami A, Al-Qahtani S, Bashanfar M, El-Khatib M, Ahmed Y, Zagzoog F. Social media and the orthopaedic surgeon: a mixed methods study. Acta Inform Med. 2019;27(1): 23-8.

27 Bahkali S, Almaiman A, Bahkali A, Almaiman $S$, Househ M, Alsurimi K. The role of social media in promoting women's health education in Saudi Arabia. Stud Health Technol Inform. 2015;213:259-62. Epub 2015 Jul 15. PubMed PMID: 26153009.

28 Almaiman S, Bahkali S, Al Farhan A, Bamuhair S, Househ M, Alsurimi K. The prevalence of using social media among healthcare professionals in Saudi Arabia: a pilot study. Stud Health Technol Inform. 2015;213:263-6. Epub 2015 Jul 15. PubMed PMID: 26153010.

29 Alanzi T. Role of social media in diabetes management in the Middle East region: systematic review. J Med Internet Res. 2018; 20(2):e58. Epub 2018 Feb 15. PubMed PMID: 29439941; PubMed Central PMCID: PMCPMC5829453.
30 Alsobayel $\mathrm{H}$. Use of social media for professional development by health care professionals: a cross-sectional web-based survey. JMIR Med Educ. 2016;2(2):e15. Epub 2016 Oct 13. PubMed PMID: 27731855; PubMed Central PMCID: PMCPMC5053809.

31 Alanzi T, Alfuraikh A. Do health care providers pay attention to sharing hospital patient safety incidents through social media in Saudi Arabia? J Patient Saf. 2020 Jun 16. Epub ahead of print.

32 Iftikhar R, Abaalkhail B. Health-seeking influence reflected by online health-related messages received on social media: cross-sectional survey. J Med Internet Res. 2017; 19(11):e382. Epub 2017 Nov 18. PubMed PMID: 29146568; PubMed Central PMCID: PMCPMC5709655.

33 Bahkali S, Alfurih S, Aldremly M, Alzayyat M, Alsurimi K, Househ M. The prevalence of internet and social media based medication information seeking behavior in Saudi Arabia. Stud Health Technol Inform. 2016;226:2758. Epub 2016 Jun 29. PubMed PMID: 27350524.

34 Zhang MW, Tran BX, Le HT, Nguyen HD, Nguyen CT, Tran TD, et al. Perceptions of health-related information on facebook: cross-sectional study among vietnamese youths. Interact J Med Res. 2017;6(2):e16. Epub 2017 Sep 9. PubMed PMID: 28882813; PubMed Central PMCID: PMCPMC5608988.

35 Ghweeba M, Lindenmeyer A, Shishi S, Abbas M, Waheed A, Amer S. What predicts online health information-seeking behavior among Egyptian adults? A cross-sectional study. J Med Internet Res. 2017;19(6):e216. Epub 2017 Jun 24. PubMed PMID: 28642216; PubMed Central PMCID: PMCPMC5500779.

36 Campbell L, Evans Y, Pumper M, Moreno MA. Social media use by physicians: a qualitative study of the new frontier of medicine. BMC Med Inform Decis Mak. 2016;16:91. Epub 2016 Jul 16. PubMed PMID: 27418201; PubMed Central PMCID: PMCPMC4946237.

37 Klee D, Covey C, Zhong L. Social media beliefs and usage among family medicine residents and practicing family physicians. Fam Med. 2015;47(3):222-6. Epub 2015 Apr 9. PubMed PMID: 25853534.

38 Hausmann JS, Touloumtzis C, White MT, Colbert JA, Gooding HC. Adolescent and young adult use of social media for health and its implications. J Adolesc Health. 2017;60(6): 714-9. Epub 2017 Mar 6. PubMed PMID: 28259620; PubMed Central PMCID: PMCPMC5441939.

39 Merolli M, Gray K, Martin-Sanchez F, LopezCampos G. Patient-reported outcomes and therapeutic affordances of social media: findings from a global online survey of people with chronic pain. J Med Internet Res. 2015; 17(1):e20. Epub 2015 Jan 24. PubMed PMID: 25616273; PubMed Central PMCID: PMCPMC4319091. 
40 Griffis HM, Kilaru AS, Werner RM, Asch DA, Hershey JC, Hill S, et al. Use of social media across US hospitals: descriptive analysis of adoption and utilization. J Med Internet Res. 2014;16(11):e264. Epub 2014 Nov 29. PubMed PMID: 25431831; PubMed Central PMCID: PMCPMC4260061.

41 Bahkali S, Alkharjy N, Alowairdy M, Househ $\mathrm{M}, \mathrm{Da}$ 'ar O, Alsurimi K. A social media campaign to promote breastfeeding among Saudi Women: a web-based survey study. Stud Health Technol Inform. 2015;213:247-50. Epub 2015 Jul 15. PubMed PMID: 26153006.

42 Wu T, Deng Z, Zhang D, Buchanan PR, Zha $D$, Wang R. Seeking and using intention of health information from doctors in social media: the effect of doctor-consumer interaction. Int J Med Inform. 2018;115:106-13. Epub 2018 May 22. PubMed PMID: 29779712.

43 Sadah SA, Shahbazi M, Wiley MT, Hristidis V. Demographic-based content analysis of web-based health-related social media. J Med Internet Res. 2016;18(6):e148. Epub 2016 Jun 15. PubMed PMID: 27296242; PubMed Central PMCID: PMCPMC4923586.

44 Yibai Li XW, Xiaolin L. Mohammad Hajli seeking and sharing health information on social media: a net valence model and crosscultural comparison. Technol Forecast Soc Change. 2018;126:28-40.
45 Giordano V, Koch H, Godoy-Santos A, Dias Belangero W, Esteves Santos Pires R, Labronici P. WhatsApp messenger as an adjunctive tool for telemedicine: an overview. Interact Med Res. 2017;6(2):e11. Epub 2017 Jul 25. PubMed PMID: 28733273; PubMed Central PMCID: PMCPMC5544893.

46 Yonker LM, Zan S, Scirica CV, Jethwani K, Kinane TB. "Friending" teens: systematic review of social media in adolescent and young adult health care. J Med Internet Res. 2015; 17(1):e4. Epub 2015 Jan 7. PubMed PMID: 25560751; PubMed Central PMCID: PMCPMC4376201.

47 De Angelis G, Wells GA, Davies B, King J, Shallwani SM, McEwan J, et al. The use of social media among health professionals to facilitate chronic disease self-management with their patients: a systematic review. Digit Health. 2018;4:2055207618771416. Epub 2018 Jun 27. PubMed PMID: 29942633; PubMed Central PMCID: PMCPMC6016564.

48 Health Mo. MoH: All the Kingdom Will be Covered by Telemedicine in Two Months 2018 [cited 2020 Aug 18]. Available from: https: //www.moh.gov.sa/en/Ministry/MediaCenter/News/Pages/news-2018-03-06-006. aspx.
49 Health Mo. (Mawid) Service 2020 [cited 2020 Aug 18]. Available from: https://www.moh. gov.sa/en/eServices/Pages/cassystem.aspx.

50 Health Mo. E-Prescription Service 2020 [cited 2020 Aug 18]. Available from: https://www. moh.gov.sa/en/eServices/Pages/Prescriptions.aspx.

51 Health Mo. MOH: Over 2,900,000 Calls Handled by 937 Call Center in July 2020 [cited 2020 Aug 18]. Available from: https://www. moh.gov.sa/en/Ministry/MediaCenter/ News/Pages/News-2020-08-13-001.aspx.

52 Health Mo. MOH: Over 2M Beneficiaries of «Takkad» Centers and «Tetamman» Clinics 2020 [cited 2020 Aug 18]. Available from: https: //www.moh.gov.sa/en/Ministry/MediaCenter/News/Pages/News-2020-08-12-007. aspx.

53 Health Mo. (Tetamman) App. 2020. [cited 2020 Aug 18]. Available from: https://www. moh.gov.sa/en/eServices/Pages/Rest-assured.aspx.

54 Alalawi A, Aljuaid H, Natto ZS. The Effect Of Social Media On The Choice Of Dental Patients: A Cross-Sectional Study In The City Of Jeddah, Saudi Arabia. Patient Prefer Adherence. 2019; 13: 1685-92. http://dx.doi. org/10.2147/PPA.S213704. 